\title{
Cultural tendencies in negotiation: A comparison of Finland, India, Mexico, Turkey, and the United States
}

\author{
Lynn E. Metcalf $^{\mathrm{a}}$ Allan Bird $^{\mathrm{b}}$ Mahesh Shankarmahesh $^{\mathrm{b}}$ Zeynep Aycan $^{\mathrm{c}}$ \\ Jorma Larimo $^{\mathrm{d}}$ Dídimo Dewar Valdelamar $^{\mathrm{e}}$

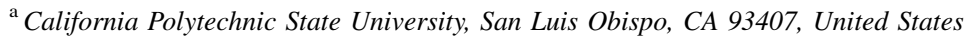 \\ ${ }^{\mathrm{b}}$ University of Missouri, 1 University Blvd., Saint Louis, MO 63121-4499, United States \\ ${ }^{\mathrm{c}}$ Department of Psychology, Rumelifeneri Yolu, Koç University, 34450 Sariyer Istanbul, Turkey \\ ${ }^{\mathrm{d}}$ Faculty of Business Studies, University of Vaasa, P.O. Box 700/Wolffintie 34, 65101 Vaasa/65200 Vaasa, Finland \\ ${ }^{\mathrm{e}}$ School of Business and Social Sciences, Tecnológico de Monterrey, Campus Cuernavaca, Avenida Paseo de la Reforma 182-A, \\ Col. Lomas de Cuernavaca, C.P. 62589, Temixco, Morelos, Mexico
}

\begin{abstract}
In this era of increased global cooperation, a growing number of negotiators conduct business in multiple countries and, therefore, need access to a systematic comparison of negotiating tendencies across a wide range of countries. Empirical work systematically comparing variations across a range of cultures is scarce. A comparative analysis of negotiating tendencies in five countries is presented. This study establishes the utility of the [Salacuse, J. (1998) Ten ways that culture affects negotiating style: Some survey results. Negotiation Journal, 14(3): 221-235] framework in identifying country differences across five countries, representing five cultural clusters. Significant differences in negotiation orientations both between and within cultures were revealed at a level of complexity not found in previous empirical studies.
\end{abstract}

In an era characterized by enormous proliferation of trade and professional ties across borders (cf. Berton, Kimura, \& Zartman, 1999; Brett, 2001; Cellich \& Jain, 2004; Cohen, 1997; Foster, 1992), international negotiation has received increasing attention. While international negotiations used to be limited to a skilled corps of diplomats, the ease of international travel, communication and transportation has widened the circle of international actors to include individuals from all walks of life-businesspeople, engineers, scientists, and people engaged in humanitarian aid. This unprecedented level of cooperation across borders increases possibilities for misunderstanding caused by variations in negotiating behaviors that are grounded in cultural differences (Cohen, 1997; Faure, 1999).

The effects of cross-cultural differences on international negotiation are widely acknowledged. Cohen (1997) notes that cultural factors can complicate, prolong, and frustrate negotiations. While there is substantial empirical evidence that negotiating tendencies differ by culture (cf. Adair, Okumura, \& Brett, 
2001; Graham, Mintu, \& Rodgers, 1994), much of the information that is available to an expanding corps of international negotiators about negotiating behaviors in countries around the world is descriptive (Elashmawi, 2001; Foster, 1992; Gesteland, 1999; Moran \& Stripp, 1991; Morrison, Conaway, \& Borden, 1994; Salacuse, 2003). Negotiators may find themselves relying on very basic lists of do's and don'ts (cf. CultureGrams, 2005; Morrison et al., 1994), which may or may not contain tips relevant to negotiating. Moreover, the items included in the lists are generally not comparable across countries. Empirical work that systematically compares variations across a range of cultures is scarce (Metcalf \& Bird, 2004). An example of what is available for the five countries that are the subject of this study is presented in Table 1 . What the data in this table makes clear is the lack of information on countries, the stereotypical nature of what is available, and the contradictions that exist - without explanation between widely available sources. In this era of increased global cooperation, it is imperative that negotiators be equipped with a better understanding of the behaviors they might expect at the negotiation table. Negotiators need information about the negotiating behaviors they are likely to encounter in a given country and, because a growing cadre of negotiators conducts business in several, or even many, different countries, there is also a need for access to a systematic comparison of negotiating tendencies across a wide range of countries.

A number of models that capture the myriad influences on international negotiating behavior and that would permit comparisons between countries have been proposed (cf. Berton et al., 1999; Cellich \&

Table 1

Conventional wisdom about negotiation in five countries ${ }^{\mathrm{a}}$

\begin{tabular}{|c|c|c|c|c|c|}
\hline Dimension & Finland & India & Mexico & Turkey & United States \\
\hline $\begin{array}{l}\text { Goal: contract or } \\
\text { relationship }\end{array}$ & & $\begin{array}{l}\text { Business in India is } \\
\text { personal, establish } \\
\text { relationships }\end{array}$ & $\begin{array}{l}\text { Mexicans seek } \\
\text { long-term } \\
\text { relationships }\end{array}$ & $\begin{array}{l}\text { Establish relationships } \\
\text { before negotiating }\end{array}$ & $\begin{array}{l}\text { Establish rapport } \\
\text { quickly; then move } \\
\text { to negotiating }\end{array}$ \\
\hline $\begin{array}{l}\text { Attitude: win/lose } \\
\text { or win/win }\end{array}$ & & & $\begin{array}{l}\text { Mexicans have a } \\
\text { win-win attitude }\end{array}$ & & $\begin{array}{l}\text { Look for mutual } \\
\text { gains, whenever } \\
\text { possible }\end{array}$ \\
\hline $\begin{array}{l}\text { Personal style: } \\
\text { informal or } \\
\text { formal }\end{array}$ & & $\begin{array}{l}\text { Negotiations follow } \\
\text { formal procedures, } \\
\text { but the atmosphere } \\
\text { is friendly and } \\
\text { relaxed }\end{array}$ & $\begin{array}{l}\text { Established etiquette } \\
\text { must be followed }\end{array}$ & & $\begin{array}{l}\text { Americans do not } \\
\text { like formality or } \\
\text { rituals in business } \\
\text { interaction }\end{array}$ \\
\hline $\begin{array}{l}\text { Communication: } \\
\text { direct or indirect }\end{array}$ & Finns are direct & $\begin{array}{l}\text { "No" is harsh. } \\
\text { Evasive refusals } \\
\text { are common } \\
\text { and more polite }\end{array}$ & $\begin{array}{l}\text { Mexican negotiators } \\
\text { may seem indirect } \\
\text { and avoid saying "no" }\end{array}$ & Politeness is important & $\begin{array}{l}\text { Be direct and to } \\
\text { the point }\end{array}$ \\
\hline $\begin{array}{l}\text { Time sensitivity: } \\
\text { high or low }\end{array}$ & $\begin{array}{l}\text { Finns begin } \\
\text { business right } \\
\text { away, without } \\
\text { small talk. It is } \\
\text { not appropriate } \\
\text { to be late }\end{array}$ & $\begin{array}{l}\text { Indians conduct } \\
\text { business at a } \\
\text { leisurely pace. } \\
\text { "Time-is-money" } \\
\text { is an alien concept }\end{array}$ & $\begin{array}{l}\text { The business atmosphere } \\
\text { is easy going }\end{array}$ & $\begin{array}{l}\text { Do not expect to } \\
\text { get right down to } \\
\text { business. The pace } \\
\text { of meetings and } \\
\text { negotiations is slow }\end{array}$ & $\begin{array}{l}\text { US negotiators } \\
\text { expect quick } \\
\text { decisions and } \\
\text { solutions }\end{array}$ \\
\hline $\begin{array}{c}\text { Emotionalism: } \\
\text { high or low }\end{array}$ & $\begin{array}{l}\text { Use objective } \\
\text { facts, rather } \\
\text { than subjective } \\
\text { feelings. Serious } \\
\text { and reserved }\end{array}$ & $\begin{array}{l}\text { Facts are less } \\
\text { persuasive } \\
\text { than feelings }\end{array}$ & $\begin{array}{l}\text { Truth is based on feelings. } \\
\text { Emotional arguments are } \\
\text { more effective than logic }\end{array}$ & $\begin{array}{l}\text { Turks show emotion. } \\
\text { Feelings carry more } \\
\text { weight than } \\
\text { objective facts }\end{array}$ & $\begin{array}{l}\text { Subjective feelings } \\
\text { are not considered } \\
\text { "facts." Points } \\
\text { are made by } \\
\text { accumulating facts }\end{array}$ \\
\hline $\begin{array}{l}\text { Team organization: } \\
\text { one leader } \\
\text { or consensus }\end{array}$ & $\begin{array}{l}\text { Individuals are } \\
\text { responsible for } \\
\text { decisions }\end{array}$ & $\begin{array}{l}\text { Decisions will be } \\
\text { made at the top }\end{array}$ & $\begin{array}{l}\text { Authority is vested in } \\
\text { a few at the top. } \\
\text { Mexicans prefer consensus }\end{array}$ & & $\begin{array}{l}\text { Individuals with } \\
\text { relevant knowledge } \\
\text { and skills make } \\
\text { decisions }\end{array}$ \\
\hline $\begin{array}{l}\text { Risk taking: } \\
\text { high or low }\end{array}$ & & Indians take risks & Mexicans avoid risk & Turks take risks & \\
\hline
\end{tabular}

a These recommendations are drawn from a variety of sources including Business Mexico, 2002; CultureGrams; Elashmawi (2001), Fisher and Ury (1991), Hall and Hall (1990), Hampden-Turner and Trompenaars (2000), Investor's Business Daily (2004), Kras (1989), Lewis (2004), Moran and Stripp (1991). 
Jain, 2004; Cohen, 1997; Salacuse, 1991; Weiss \& Stripp, 1985). These models can be classified according to the comparative, micro-behavioral (cross-cultural) paradigm identified by Weiss (2004) in his review of the international negotiation literature. This micro-behavioral paradigm directs attention to the face-to-face interaction between negotiators, with particular interest in the orientations and behaviors of negotiators, as well as the effect of contextual factors. Streams of research on this paradigm include the work of Graham and his associates on intracultural negotiation and Brett and her associates on intercultural negotiation. These bodies of work, while shedding light on cultural differences in negotiating behaviors, limited their focus to not more than three negotiating tendencies. The only framework that has been empirically investigated in full is the Salacuse (1991) framework (see Fig. 1). It includes ten negotiating tendencies and allows for a range of possible responses along each bi-polar continuum.

The research reported in this article involves a comparative analysis of negotiating tendencies in five countries, based on the ten dimensions in the Salacuse framework. Our objectives are twofold. First, we test the utility of the ten dimensions in identifying country differences, employing sample sizes sufficient to allow for multivariate statistical analysis. Second, we identify the specific dimensions on which country differences are likely to be found.

\section{Method}

\subsection{Country selection}

With the intent of establishing variation between cultures, the five countries selected for consideration in this study are drawn from different cultural clusters. Ronen and Shenkar (1985) originally proposed the

\begin{tabular}{|c|c|c|}
\hline Negotiation Factors & Range of $\mathrm{C}$ & Iltural Responses \\
\hline Goal & Contract & Relationship \\
\hline Attitudes & Win/Lose & Win/Win \\
\hline Personal Styles & Informal & Formal \\
\hline Communications & Direct & Indirect \\
\hline Time Sensitivity & High & Low \\
\hline Emotionalism & High & Low \\
\hline Agreement Form & Specific & General \\
\hline Agreement Building & Bottom Up & Top Down \\
\hline Team Organization & One Leader & Consensus \\
\hline Risk Taking & High & $\rightarrow \quad$ Low \\
\hline
\end{tabular}

Fig. 1. Dimensions of cultural variation in negotiation. notion of cultural clusters and, more recently, the GLOBE research project (House, Hanges, Javidan, Dorfman, \& Gupta, 2004) adopted a similar cluster approach. The premise underlying cultural clusters is that due to reasons of geographic proximity, common language and historical relatedness, similarities in values and beliefs, there may be found similarities among national cultures. Five cultural clusters are represented in this study: Finland is classified in the Nordic/Scandinavian cluster, Turkey in the Near Eastern/Middle Eastern cluster; Mexico in the Latin American cluster; the USA in the Anglo cluster; and India in the Southern Asia cluster (House et al., 2004; Ronen \& Shenkar, 1985).

\subsection{Survey instrument}

To measure negotiating tendencies, Salacuse employed a survey instrument that included ten bipolar dimensions measured on five-point scales. ${ }^{5}$ Respondents were instructed to indicate where their own negotiating style and approach to business negotiations fell along each of the ten continua. In his 1998 study, Salacuse reported results from a survey of 191 respondents from 12 countries. Limitations to the study noted by Salacuse include the size of the sample (191/12 yields an average of 16 respondents per country) and the fact that respondents completed the survey in English. To overcome these limitations, we sought significantly larger samples and translated the English-language survey into Mexican Spanish, Finnish and Turkish using translators in each country. To ensure that items were accurately translated, bi-lingual scholars familiar with concepts of cross-cultural negotiation compared each translation to the English original.

The survey method has been widely used in the negotiation literature (cf. Ganesan, 1993; Perdue \& Summers, 1991) and in large-scale research projects comprising multiple countries (cf. House et al., 2004). While negotiation experiments conducted in a lab setting may yield focused insight into several variables, surveys enable researchers to collect data over a broader range of variables. Moreover, surveys are less cumbersome to conduct across multiple countries and multiple investigators. The survey method does assume that respondents are truthful regarding their preferences.

\footnotetext{
${ }^{5}$ For instance, on the goal dimension, contract $=1$ and relationship $=5$.
} 


\subsection{Subjects}

A sample of business people and university students with business experience was drawn from Finland, India, Mexico, Turkey, and the USA. The results presented below are based on responses from 147 men and women from Finland, 196 from India, 327 from Turkey, 192 from Mexico, and 327 from the USA.

Chi-square test results show demographic differences between the samples. Finnish and Indian respondents were predominantly male, whereas the genders of respondents from the other three countries were more evenly divided. US and Indian respondents were younger than Mexican and Turkish respondents. Indian respondents were better educated than the respondents from the other four countries. Finally, $45 \%$ of the Indian sample reported having either middle management or top-level executive experience, with $39 \%$ for Mexico, $28 \%$ for Turkey, $14 \%$ for the US, and $12 \%$ for Finland. Differing demographic profiles across countries is not uncommon in multi-country studies (cf. the GLOBE project). This issue has been acknowledged in prior research involving multiple countries and multiple investigators. In our analyses, national differences in negotiation orientations remained after controlling for demographic differences. Recognizing the variance in demographic characteristics across country samples, the data still provide useful insights into intra- and intercultural variation in negotiating tendencies.

\subsection{Data analysis}

To test whether respondents' country of origin accounted for differences in the ten negotiating orientations, we conducted a MANOVA analysis. The results were significant, indicating that country differences in negotiating tendencies exist. Mean scores for each country on each of the 10 negotiating tendencies are reported in Table 2. To test for country differences individually across each of the ten negotiating tendencies, we used Tukey's Honestly Significant Difference Test. This is a more powerful post hoc multiple comparison test for testing a large number of pairs of means (Winer, Michels, \& Brown, 1991). Tukey's HSD results are also presented in Table 2.

Before meaningful cross-cultural comparisons can be made, response bias - a systematic tendency to distort responses to rating scales either by selecting extreme or modest answers - must be addressed (Van de Vijver \& Leung, 1997). Recently, researchers have been urged to seek theoretical explanations for differences in

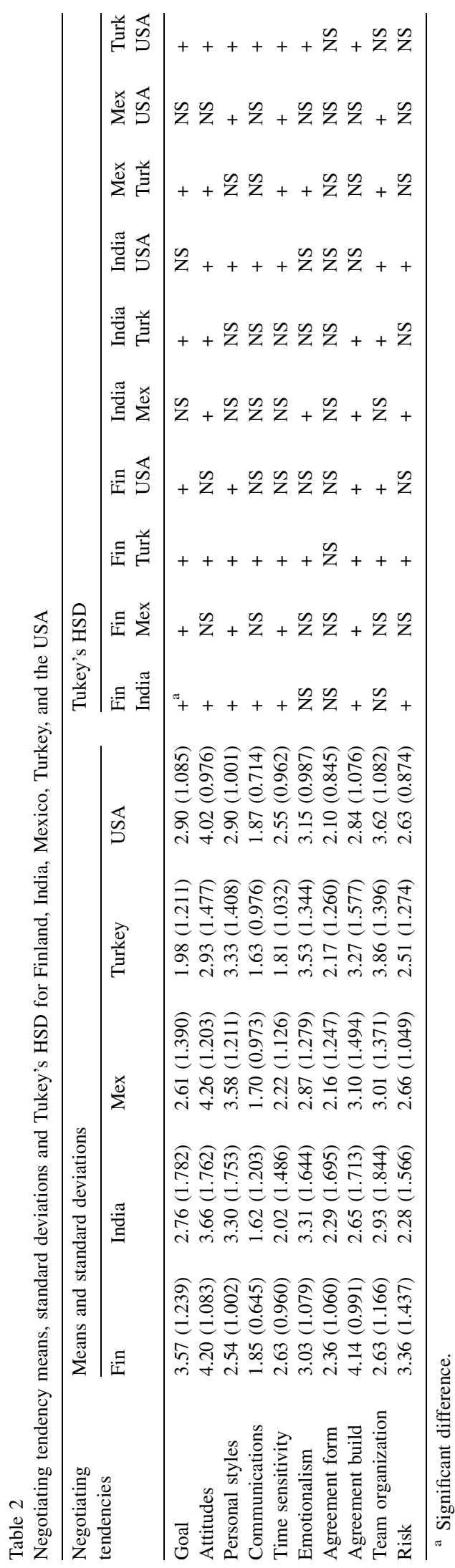


patterns of response rather than immediately conclude that such differences are a result of response bias (Fischer, 2004; Smith, 2004). In the results reported in Table 3 and our ensuing discussion, reasonable research-based explanations are provided for the different patterns of response found among the five countries studied.

In addition to reporting mean scores, Au (1999) urged international business researchers to take a closer look at the dispersion of responses within a given culture. Intra-cultural variation (ICV), measured by the standard deviation, can help capture critical crosscultural differences. Results show that ICV for India was consistently larger than the other four countries across all ten negotiating tendencies. In contrast, ICV for the US was the smallest among the five countries for seven of the ten negotiating tendencies. We will return to a consideration of ICV in our discussion of the results.

\section{Results}

It is common, when reporting the results of statistical analyses employing two or more techniques, to discuss the findings derived from each technique. The nature of our investigation and our interest in within- and well as between-culture variation led to us to examine the intersection of two sets of results: (1) comparisons of means and standard deviations between pairs of countries and (2) comparisons of within-country response distributions. We focus first on results for each negotiation dimension, and then move on to a consideration of the broader findings.

\subsection{Goal: contract or relationship?}

This dimension refers to the primary goal of a business negotiation: to arrive at a signed contract or to build a relationship between the two parties (Salacuse, 2003). Chi-square test results show a significant difference among the distribution of responses for each country on this behavior (see Table 3). Turkish respondents showed the strongest preference for leaving the negotiating table with a contract, while Finns showed a stronger orientation toward building a relationship. These two countries occupied opposing positions on the distribution, with the other three falling somewhere in the middle. Results for India were mixed, with $39 \%$ of respondents preferring to arrive at a signed contract and $34 \%$ preferring to build a relationship. Mexican respondents showed a stronger preference for arriving at a signed contract, and US respondents centered their responses between the two poles Sizeable percentages of US respondents were also found in the "neither" and "slight preference for a relationship" response categories.

\subsection{Attitude: win-lose or win-win?}

Business negotiators tend to approach a negotiation with one of two basic attitudes: it is either a process where both parties can gain or a struggle in which there is a winner and a loser (Salacuse, 2003). Turkish and Indian respondents showed the strongest preference for win-lose outcomes. With that said, Turkish respondents were fairly evenly divided, and somewhat evenly distributed across the win-lose/win-win continuum, whereas Indian respondents demonstrated either a clear preference for a win-win or a win-lose outcome. Respondents from Finland, Mexico, and the US demonstrated a greater preference for win-win results, with Mexicans least likely to prefer a win-lose result. Of ten paired comparisons, seven were statistically significant in difference on this dimension (see Table 2).

\subsection{Personal style: informal or formal?}

This dimension refers to the way in which business negotiators talk to and interact with others, use titles, and dress (Salacuse, 2003). Respondents from India were clear in their preference for a more formal personal style, with respondents from Mexico and Turkey following suit, although not as strongly. By contrast, over half of the Finnish respondents preferred an informal personal style. Preferences of US respondents were less strong, with the tendency toward formality nearly as strong as the tendency toward informality. Results reported in Table 2 show statistically significant differences on seven of the 10 paired comparisons.

\subsection{Communication: direct or indirect?}

Negotiators from some countries prefer direct and simple communication, while others employ an indirect, more complex style of communication (Salacuse, 2003). Chi-square tests between pairs of countries show that the patterns of response for Finland and the USA, as well as for Mexico and Turkey were similar (see Table 3). While respondents from all countries largely prefer a direct communication style, there are interesting and unexpected differences in the response patterns. Indian respondents demonstrated the strongest preference $(71 \%)$ for a direct style of 
Table 3

Percentage distributions for ten dimensions

\begin{tabular}{|c|c|c|c|c|c|c|}
\hline Dimension & Finland & India & Mexico & Turkey & $U S A$ & $X^{2^{*}}$ \\
\hline \multicolumn{6}{|l|}{ 1. Goal } & \multirow{6}{*}{388.681} \\
\hline \multirow[t]{2}{*}{ Contract } & 6 & $39^{\dagger}$ & 27 & 43 & 9 & \\
\hline & 15 & 12 & 25 & 28 & 30 & \\
\hline \multirow{2}{*}{ Neither } & 12 & 10 & 23 & 16 & 28 & \\
\hline & 44 & 5 & 11 & 5 & 27 & \\
\hline Relationship & 22 & 34 & 15 & 7 & 6 & \\
\hline \multicolumn{6}{|l|}{ 2. Attitudes } & \multirow{6}{*}{352.905} \\
\hline \multirow[t]{2}{*}{ Win/Lose } & 1 & 27 & 5 & 26 & 2 & \\
\hline & 3 & 5 & 6 & 13 & 6 & \\
\hline \multirow[t]{2}{*}{ Neither } & 11 & 5 & 6 & 16 & 18 & \\
\hline & 34 & 4 & 20 & 28 & 37 & \\
\hline Win/Win & 49 & 59 & 63 & 16 & 38 & \\
\hline \multicolumn{6}{|c|}{ 3. Personal Style } & \multirow[t]{6}{*}{325.202} \\
\hline \multirow[t]{2}{*}{ Informal } & 10 & 28 & 7 & 13 & 8 & \\
\hline & 42 & 6 & 13 & 18 & 27 & \\
\hline \multirow[t]{2}{*}{ Neither } & 27 & 13 & 25 & 18 & 36 & \\
\hline & 17 & 7 & 28 & 22 & 25 & \\
\hline Formal & 2 & 45 & 28 & 28 & 4 & \\
\hline \multicolumn{6}{|c|}{ 4. Communication } & \multirow{6}{*}{215.409} \\
\hline Direct & 26 & 71 & 54 & 58 & 29 & \\
\hline & 63 & 11 & 31 & 28 & 57 & \\
\hline \multirow[t]{2}{*}{ Neither } & 10 & 9 & 8 & 8 & 12 & \\
\hline & 1 & 1 & 3 & 2 & 2 & \\
\hline Indirect & 0 & 8 & 3 & 4 & 1 & \\
\hline 5. Time Sensiti & & & & & & 313.657 \\
\hline High & 10 & 59 & 30 & 49 & 13 & \\
\hline & 38 & 15 & 36 & 31 & 37 & \\
\hline Neither & 31 & 6 & 21 & 12 & 35 & \\
\hline & 20 & 5 & 7 & 5 & 13 & \\
\hline Low & 1 & 15 & 6 & 3 & 3 & \\
\hline 6. Emotionalis! & & & & & & 242.486 \\
\hline High & 5 & 24 & 16 & 11 & 4 & 292.700 \\
\hline & 28 & 9 & 26 & 10 & 22 & \\
\hline Neither & 31 & 19 & 27 & 21 & 37 & \\
\hline & 27 & 7 & 17 & 26 & 29 & \\
\hline Low & 8 & 41 & 14 & 30 & 8 & \\
\hline Dimension & Finland & India & Mexico & Turkey & $U S A$ & $X^{2^{*}}$ \\
\hline 7. Agreement 1 & & & & & & 259.314 \\
\hline Specific & 18 & 55 & 39 & 36 & 22 & \\
\hline & 47 & 11 & 30 & 33 & 54 & \\
\hline Neither & 14 & 6 & 16 & 15 & 17 & \\
\hline & 18 & 3 & 7 & 6 & 6 & \\
\hline General & 2 & 25 & 8 & 9 & 1 & \\
\hline 8. Agreement $B$ & ilding & & & & & 262.543 \\
\hline Bottom Up & 1 & 43 & 22 & 19 & 9 & ניד \\
\hline & 6 & 11 & 15 & 16 & 32 & \\
\hline Neither & 7 & 10 & 20 & 13 & 33 & \\
\hline & 45 & 8 & 18 & 18 & 17 & \\
\hline Top Down & 40 & 27 & 26 & 34 & 8 & \\
\hline 9. Team Organ & ation & & & & & 394.490 \\
\hline One Leader & 16 & 41 & 14 & 10 & 3 & \\
\hline & 31 & 8 & 31 & 10 & 15 & \\
\hline Neither & 22 & 5 & 17 & 10 & 20 & \\
\hline & 26 & 6 & 17 & 23 & 40 & \\
\hline Consensus & 3 & 39 & 21 & 48 & 22 & \\
\hline 10. Risk-Taking & & & & & & 319.389 \\
\hline High & 1 & 49 & 13 & 25 & 7 & \\
\hline & 27 & 12 & 34 & 27 & 40 & \\
\hline Neither & 46 & 16 & 36 & 29 & 38 & \\
\hline & 22 & 4 & 12 & 7 & 13 & \\
\hline Low & 2 & 19 & 6 & 11 & 2 & \\
\hline
\end{tabular}

(*) All $\chi^{2}$ scores are with 20 degrees of freedom, significant at $p=.000$. (†) Cells with results of 33 percent or higher are shaded for emphasis. 
communication, followed by Turkey and Mexico. Surprisingly, although US respondents clearly favor direct communication, their orientation was the least pronounced of the five countries.

\subsection{Time sensitivity: high or low?}

Salacuse (2003) refers to whether negotiators from a given country are punctual or late and whether negotiators from a particular country negotiate slowly or are quick to make a deal. The Chi-square test results show a significant difference among countries on time sensitivity (see Table 3 ) and paired comparisons show significant differences on seven of the ten combinations. At least half of the respondents from all countries demonstrate sensitivity toward time. Perhaps most noteworthy is that the Indian respondents (59\%) show the strongest sensitivity, followed by Turkish and then Mexican respondents. Also of interest is the finding that $15 \%$ of Indian respondents - the largest percentage reported in this category for any country - also reported low sensitivity toward time.

\subsection{Emotionalism: high or low?}

The tendency to act emotionally and/or to display emotions while negotiating is captured in Salacuse's (2003) sixth dimension. Though Indian respondents report the strongest tendency not to display emotions, as well as the strongest tendency to display emotions, the distribution of Indian responses is essentially tri-modal, with another sizeable group (19\%) occupying the center of the distribution. Turkish respondents also tended toward low emotionalism. In contrast, Finland and the US had distributions that were clearly anchored in the middle, and Mexico's distribution was skewed somewhat toward emotionalism.

\subsection{Agreement form: specific or general?}

This dimension refers to the degree to which the final agreement between the parties includes detailed clauses that attempt to provide specifically for as many future events and risks as possible (Salacuse, 2003). While at least two-thirds of the respondents from each country preferred a specific agreement, the strength of the preference varied across countries (see Table 3). Indian respondents demonstrated the strongest preference (55\%) for a specific agreement, followed by Mexico and Turkish respondents. Finnish and US respondents demonstrated a weaker preference for specific agreements but were also least likely to prefer a general agreement. We again found a bimodal response pattern for Indian, with $25 \%$ preferring a general agreement. It should also be pointed out, as reflected in Table 2, that there were no statistically significant differences in mean scores between pairs of countries.

\subsection{Agreement building: bottom up or top down?}

This dimension captures whether negotiators build agreement by negotiating specifics, such as product characteristics, price, and terms of delivery, or whether they start from general principles and then proceed to specific items (Salacuse, 2003). Finnish respondents strongly preferred a top down approach, with $85 \%$ positioned on that end of the continuum (see Table 3 ). Indian responses stood in sharp contrast with more than $50 \%$ preferring a bottom-up approach, although once again a sizeable portion (27\%) located at the top-down end. The Turkish response pattern leaned toward a topdown approach, while Mexican and US patterns reflected no strong preference. Paired comparisons reported in Table 2 show statistically significant differences on seven of the ten combinations.

\subsection{Team organization: one leader or consensus?}

Some negotiating teams are led by one individual possessing complete authority to decide matters, while others stress team consensus in decision-making (Salacuse, 2003). Turkish respondents reported the strongest tendency to stress team negotiation and consensus decision-making, with more than $70 \%$ of respondents leaning in that direction (see Table 3). A sizeable percentage of US respondents also reported preference for consensus decision-making. Indian respondents were split almost evenly between consensus and one leader. Finnish and Mexican respondents do not indicate a strong preference in either direction, but appear to lean toward the "one-leader" end of the scale.

\subsection{Risk-taking: high or low?}

Salacuse (2003) notes that negotiators from some countries are more risk averse than others. With the exception of Finland, a large percentage of respondents from each country favor a risk-taking approach (see Table 3). Indian respondents are the most likely to strongly favor a risk taking approach, followed by Turkish respondents. US and Mexican respondents were least likely to have a strong preference for a risk-taking approach, though they clearly leaned in that direction. 
In contrast, Finnish respondents anchored themselves clearly in a balanced position between risk-taking and risk-averse, with $46 \%$ at the midpoint.

\section{Discussion and implications}

Our objectives for this study were twofold. First, we sought to establish the utility of the Salacuse framework in identifying country negotiating differences. Second, we sought to identify the specific dimensions on which countries differ. We did, indeed, find significant differences between Finland, India, Mexico, Turkey, and the USA. Additionally, the pattern of responses across the ten dimensions was unique for each country. Specific country differences were identified using pairwise tests. For five of the dimensions - Goal, Attitude, Personal Styles, Time Sensitivity, and Agreement Building - we found significant differences on seven of the 10 paired comparisons. In only one case Agreement Form - did we find no significant differences between the five countries.

Examining the pattern of responses for each country, we identified several interesting findings. The most significant finding is the nature and extent of ICV across the ten dimensions. India demonstrated the largest ICV across all ten dimensions. Au (1999) posited that large ICV can be explained by factors such as demographics, a low uncertainty avoidance score (Hofstede, 1981), a loose culture where there are multiple and sometimes conflicting norms governing specific behaviors, and a pervasive democratic ideology, which exposes people to a wider range of viewpoints and ways of doing things. India is a multi-lingual, multi-ethnic country, has the lowest uncertainty avoidance score among the five countries, is a loose culture, and has been a democracy for six decades. In contrast, ICV for the US was the smallest among the five countries for seven of the ten negotiating tendencies. Smaller ICV is contrary to what one might expect, given that the US has the second lowest uncertainty avoidance score among the five countries, is a loose culture, and has the oldest democracy. Yang (1988) argued that industrialization homogenizes the value systems of individuals. A small ICV for the US may be attributed to the high level of industrialization in the United States. The tendency of US respondents to avoid extremes may also be a manifestation of this country's homogenized value system.

Although each country presented a unique pattern of negotiation orientations, not surprisingly countries were found to be similar on some dimensions. For example, no significant differences were found between pairs of countries on agreement form, despite the fact that ICV that varied widely. The similarities between countries and the differences within countries - and vice-versa present the opportunity to explore further interesting findings for several dimensions.

\subsection{Goal: contract or relationship?}

Because it is rare for US parties to enter into agreements without the benefit of a contract (Kurz, 2000), one would expect the majority of US respondents to not only demonstrate a preference for contracts but also hold a stronger preference for a contract than would respondents from the other countries. This was not the case. Our findings may reflect a growing emphasis in the US on developing and maintaining long-term relationships with suppliers and customers. Although contracts are important, close relationships facilitate business processes, such as supply chain management and JIT manufacturing, that are the hallmark of today's industry leaders. On the other hand, conventional wisdom holds that Indian businesspersons generally demonstrate a basic reliance on the underlying relationship (Shroff, 2000). Yet our Indian respondents did not indicate this. In fact, a majority of them preferred a contract. India's rapid ascent as a global player and the increasing westernization of its business practices may account for our results.

A clear implication of this finding is that negotiators should realize that the goals of a signed contract and of building a relationship are not necessarily mutually exclusive and that the achievement of one can lead to the other. As business practices change over time due to global diffusion, negotiators should be wary of the conventional thinking that negotiators from the US are contract-oriented and those from India, Mexico, and Turkey are relationship-oriented.

The preceding implication, as well as those for the other nine dimensions, is presented in Table 4. Our findings suggest that negotiators should prepare differently than "conventional wisdom" regarding negotiation orientations in these five countries might suggest (refer again to Table 1). Table 4 presents a number of practical "do's" and "don'ts" that negotiators can take away from our empirical findings.

\subsection{Attitude: win/lose or win/win?}

Negotiators should not view the negotiation process as adversarial, nor should they look at it as a forum for making unilateral concessions. With the exception of Turkey, the orientation of respondents on this dimension 
Table 4

Cultural tendencies in negotiation: Implications for preparation and behavior

\begin{tabular}{|c|c|c|}
\hline Dimension & Do & Do not \\
\hline Goal: contract or relationship & Establish relationships with Finnish negotiators & $\begin{array}{l}\text { Assume that Indian, Mexican, and } \\
\text { Turkish negotiators are not focused } \\
\text { on concluding a contract }\end{array}$ \\
\hline Attitudes: win/lose or win/win & $\begin{array}{l}\text { Acquire knowledge about general attitudes } \\
\text { of individual negotiators. Turks are as } \\
\text { likely to be win-lose as win-win. Indian } \\
\text { attitudes are extreme }\end{array}$ & $\begin{array}{l}\text { Assume that a "win/win" approach } \\
\text { will be appealing. When Indians or } \\
\text { Turks adopt a win-lose attitude, } \\
\text { emphasize your concessions and } \\
\text { their gains }\end{array}$ \\
\hline Personal style: informal or formal & $\begin{array}{l}\text { Recognize that Indians, Mexicans, and } \\
\text { Turks are more likely to adhere to rules }\end{array}$ & $\begin{array}{l}\text { Ignore protocol in countries where } \\
\text { it is important }\end{array}$ \\
\hline
\end{tabular}

Communication: direct or indirect

Time sensitivity: high or low

Emotionalism: high or low

Agreement form: specific or general

Agreement building: bottom up or top down

Team organization: one leader or consensus

Risk taking: high or low that govern professional conduct, negotiating procedures, and hospitality

Discuss directly underlying issues with Finnish, Indian, Mexican, Turkish, and US negotiators

Address negotiation issues with Indian, Mexican, and Turkish negotiators in a time-bound manner

Support arguments with facts when negotiating with Indians or Turks

Negotiate specific contract terms in India, Mexico, and Turkey. Be aware that some negotiators in India will view definitive contract terms as too rigid Build momentum with Indians by negotiating agreement on smaller issues. Build rapport with Finns and lay out the general themes and principles behind the negotiations

Identify and build a strong rapport with the leader of the negotiating team in Finland and India
Expect American negotiators to use a more direct style than Indian, Mexican, or Turkish negotiators Think of Indian, Mexican, or Turkish negotiators as less sensitive to time than Americans or Finns

Expect Indian or Turkish negotiators to use emotional arguments

Expect that broad or vague contract language will be acceptable in Finland, India, Mexico, Turkey, and the US Begin negotiations with Finns and Turks by discussing details of the project

Ignore mid-level negotiators in India and Mexico. They may have the capacity to form a consensus and/or influence decisions made at the top

Assume that Mexican negotiators avoid risk was strongly tilted toward finding mutual rewards in negotiations. The sizeable percentage of Turkish respondents in each of the five response categories on this dimension suggests that when negotiating with Turks, negotiators from other countries need to explore the attitudes of the specific parties with whom they are negotiating. This, of course, is prudent advice in all negotiation settings.

\subsection{Personal style: informal or formal?}

While it is commonly believed that Americans tend to be highly informal, our findings indicate that Finns are even more so. This suggests that negotiators from the other four countries - particularly Americans should be sensitive to the level of formality they exhibit when working with Finns. Whether they are formal or informal, negotiators from all countries generally engage in informal social interactions before and/or during the formal negotiation process. It is worthwhile for negotiators to learn the boundaries between such informal social activities and formal task-specific negotiations. Friendliness exhibited during social interactions may not necessarily translate into "friendly" concession-making behavior during actual negotiations. Our findings suggest that this may be the case with Indian, Mexican and Turkish negotiators. Negotiators are advised to view what occurs in social interactions only as a guide to understanding the larger social context.

\subsection{Communication: direct or indirect?}

Given the relatively unambiguous findings on this dimension, negotiators are encouraged to engage in direct discussion of both the major and minor issues in 
the underlying negotiations. Given global diffusion of business practices, it is not a good idea to go by conventional thinking that US negotiators use a more direct style of communication than negotiators from other countries such as Turkey or India.

\subsection{Time sensitivity: high or low?}

The results on this dimension were surprising and contradict what is commonly known and understood about negotiators from each of the five countries. Most sources indicate that Mexican and Indian negotiators do not expect punctuality and tend to follow a slower pace; Turkish negotiators are punctual, yet also follow a slower pace; and "time is money" for US negotiators (Foster, 1992; Kras, 1989; Morrison et al., 1994; Salacuse, 2003; Victor, 1992). Yet greater percentages of respondents from Finland, India, Mexico, and Turkey reported a higher sensitivity toward time than US respondents. While on the surface it may be surprising that US respondents were not as sensitive to time as conventional wisdom might indicate, our findings may reflect a shift in US orientation brought about by continuous and specific criticisms of US negotiators during the 1980s and 1990s - that they were too focused on time to the detriment of social relationships (cf. Lewin et al., 1995; Lincoln and Kalleberg, 1985).

Researchers have called for businesspeople to be 'cross pollinators' and 'fertilizers' that span different cultural environments (Bartlett \& Ghoshal, 1992). The explosion in global trade over the past decade and the diffusion of best business practices across the globe may have simultaneously decreased the time sensitivities of US negotiators and increased time sensitivities of negotiators in countries, such as India and Mexico, which have traditionally held more relaxed attitudes toward time. Consequently, negotiators are advised not to think of their Indian and Mexican counterparts as less sensitive to time than negotiators from the US or Finland. In the struggle to maintain competitiveness, businesspeople dealing with partners around the world can hardly justify tardiness as a cultural characteristic. While not being punctual may still be acceptable in certain cultures for personal transactions, global business culture is increasingly time dominated. Accordingly, negotiators are advised to address both major and minor negotiation issues in a time-bound manner.

\subsection{Emotionalism: high or low?}

It is interesting to note that a rather large percentage of US and Finnish respondents preferred neither to act emotionally nor to keep their emotions under wraps. For US negotiators, this may reflect the tendency of US businesspeople to communicate objections and dissatisfaction openly and directly, with the expectation that the other party will engage in problem-solving behavior. It is important for negotiators to recognize that it may be impossible for counterparts from some countries to separate the emotional component from the task-based component on certain issues. Where possible, negotiators might be well advised to divide issues into two categories: one that contains issues with a high emotional component and another that comprises issues without a high emotional component. For issues with a large emotional component, strategies to resolve them should include informal social interactions in combination with conventional problem-solving techniques. On the other hand, issues with a low emotional component can be effectively addressed using traditional problem-solving approaches alone.

\subsection{Agreement form: specific or general?}

Given the general preference across all respondents for a specific agreement, negotiators may be well served to specify clearly the nature of agreement on both major and minor negotiation issues when negotiating in any of these five countries. Additionally, when negotiating with Indians and, to a lesser extent Finns, negotiators may also find it useful to incorporate a more general foundation as a basis for the specifics of the agreement. Moreover, inserting too many specific clauses to protect against potential liabilities in the event of a failure in the relationship can sow the seeds of suspicion and spoil opportunities to foster trust in the relationship.

\subsection{Agreement building: bottom up or top down?}

In Finland and Mexico, which favor a top-down approach to agreement-building, the general themes and principles behind negotiations can be laid out during social interactions preceding the formal negotiation process. On the other hand, in India social interactions can be used to broach specific task-related issues instead of overarching themes and principles.

\subsection{Team organization: one leader or consensus?}

Results for India and Mexico are consistent with conventional wisdom, with respondents from both countries reporting a greater preference for decisions made by a single leader. In India decisions are made at the top, but mid-level negotiators have input (Morrison 
et al., 1994). Our results show Turks as being the most consensus-oriented, a finding consistent with the GLOBE's study (House et al., 2004). GLOBE findings show that Turks place a lower value on power distance, while maintaining a high value for collectivism-a profile that fits well with the idea of consensus building in the negotiation context. Data from the most recent world values survey (Inglehart, Basañez, DíezMedrano, Halman, \& Luijkx, 2004) offer additional insight. Turkey scores very low on 'trust' towards leaders in society; therefore, relying on a single leader in negotiations may be perceived as risky. Though US negotiators are not consensus-oriented in the Japanese sense of conformity, decision-makers rely on and consider the advice of experts on the negotiating team. By contrast, in countries such as India, where negotiators tend to prefer a single-leader approach, it is important to identify and to build strong rapport with such leaders. Negotiators must also make full use of social interactions to build a platform for strong interpersonal relationships with key decision makers. In countries that prefer a consensual approach, negotiators must not ignore the roles of the other party's mid-level negotiators and technical advisors in influencing organizational decisions.

\subsection{Risk taking: high or low?}

While risk aversion and uncertainty avoidance are not equivalent concepts they are related (Hofstede, 2001). Negotiators from cultures with tendencies toward lower Uncertainty Avoidance accept not only familiar but also unfamiliar risks, whereas negotiators from cultures with high Uncertainty Avoidance (UAI) scores tend to limit the risks they take to those that are known. Turkey ranks highest on Hofstede's UAI index (85), with Mexico not far behind (82), followed by the US (46) and India (40). Results on Salacuse's risktaking dimension show US and Mexican respondents as the least likely to favor a high-risk approach to negotiating. These results are consistent with what one would expect for Mexico, given its high UAI index; however, the results for the US are not. A large percentage of US respondents fell in the "neither" category. These results may be consistent with what is generally known about US negotiators-that they are risk tolerant, showing an interest in reducing risk rather than trying to avoid it altogether. For highly risk-averse negotiators from another country, negotiators should focus on the bottom-line aspects of the contract and how the agreement can be beneficial even in "worst-case" scenarios. Even "realistic" scenarios can be perceived differently by risk-averse partners, who may be satisfied by nothing less than specific bottom-line guarantees. On the other hand, for risk-taking negotiators, one can highlight the potential upsides or best-case scenarios of the agreement.

The findings suggest several directions for future research. Some of the dimensions in the Salacuse framework are not clearly defined. For example, in his discussion of time sensitivity, Salacuse (2003) refers to two different concepts: whether negotiators from a given country are punctual or late and whether negotiators are quick to make a deal or proceed slowly. To the extent that these are conceptually separable, they should be treated as such. This calls for further theoretical development.

The dimensions identified are consistent with previous conceptualizations (Weiss \& Stripp, 1985; Metcalf \& Bird, 2004). There are, however, important differences. Extending the work of Weiss and Stripp (1985), Metcalf and Bird (2004) identify twelve negotiation dimensions, which are grouped into six categories: general model, team dynamics, communication, protocol, risk-taking, and outcomes. Five of the six categories include two or more dimensions, the lone exception being the outcomes category. Still, there is substantial overlap between the two approaches, which future research should seek to synthesize.

Before concluding, we note several limitations to this study. First, the five countries included neither represent all of the cultural clusters identified by Ronen and Shenkar (1985) or the GLOBE study (House et al., 2004) nor do they represent the full range of scores reported by Hofstede (2001) on his work-related values dimensions. The inclusion of country samples from the other cultural clusters holds the prospect for adding breadth and would help strengthen the findings reported in this study. Second, including more than one country from a given cultural cluster may yield insight into cultural variation within clusters. To that end, we are gathering data from Spain, Portugal, Germany, and Australia; and have plans for China, Japan, South Korea, and Thailand.

A second limitation of the study relates to the comparability of the samples for each country. Although it would be ideal to have samples with matched demographic profiles, it must be pointed out that obtaining such samples in international business research is difficult. This can be attributed to the challenges associated with multiple investigators collecting data in countries representing five cultural clusters. Acquiring data from additional respondents in each country, something currently underway, will allow 
us to investigate the impact of demographic characteristics on negotiating tendencies.

\section{Conclusions}

Our findings confirm that cross-national variation in negotiation tendencies can be identified. Frameworks help facilitate adjustments in negotiator expectations and increase the likelihood of positive outcomes. The use of a dimensional framework also allows for meaningful cross-national comparison. Negotiators can use the ten dimensions to systematically identify possible areas of tension, thereby making it possible to appropriately adjust their expectations and negotiation practices accordingly. Although the findings of this study are limited to five countries, because these countries are drawn from five different cultural clusters, they point to the likelihood of wider generalizability. Second, negotiators can use the framework to develop insight into their own orientations. Using risk-taking as an example, a negotiator whose response falls in the "neither" category, between risk avoidance and high risk taking, develops a more fine-grained appreciation of himself as someone who is risk tolerant, yet interested in reducing risk.

Ultimately, however, the most significant contributions of this study are the insights that are generated by the framework, not the framework itself. The framework was effective in revealing the varied and complex nature of negotiation tendencies within and between cultures. Cultures are similar on some dimensions (e.g., communication, agreement form) and different on others (e.g., agreement building). Equally important, if not more so, the findings reveal that individuals and groups within cultures may be united on some dimensions (Indians on direct communication), deeply divided or split on others (Indians on attitudes), and uncommitted on others (Finns on risk-taking). It is no longer acceptable nor is it accurate or useful - if it ever was - for, say, an American negotiator to expect a Mexican counterpart to be relationship-oriented or an American compatriot to be contract-oriented. ${ }^{6}$ Our findings point to the inherent inaccuracy of what Osland and Bird (2000) have referred to as "sophisticated stereotyping." If it is trite to note that international negotiations are highly complex affairs, then it should not come as a surprise to find that the negotiators themselves are similarly complex.

\footnotetext{
${ }^{6}$ The authors thank an anonymous reviewer for contributing these ideas.
}

\section{References}

Adair, W., Okumura, T., \& Brett, J. (2001). Negotiation behavior when cultures collide: The United States and Japan. Journal of Applied Psychology, 86(3): 371-385.

$\mathrm{Au}$, Kevin Y.. (1999). Intra-cultural variation: Evidence and implications for international business. Journal of International Business Studies, 30(4): 799-812.

Bartlett, C. A., \& Ghoshal, S. (1992). What is a global manager? Harvard Business Review, 70(5): 124-132.

Berton, P., Kimura, H., \& Zartman, I. W. (Eds.). (1999). International negotiation: Actors, structure/process, values. New York: Saint Martin's Press.

Brett, J. M. (2001). Negotiating globally: How to negotiate deals, resolve disputes, and make decisions across cultural boundaries. San Francisco: Jossey-Bass.

Business Mexico. (2002). Dealing differences, 12(7): 54-55.

Cellich, C., \& Jain, S. C. (2004). Global business negotiations: A practical guide. Mason, $\mathrm{OH}$ : Thomson South-Western.

Cohen, R. (1997). Negotiating across cultures. Washington, DC: United States Institute of Peace.

CultureGrams World Edition. (2005). Ann Arbor: ProQuest.

Elashmawi, F. (2001). Competing globally. Boston: Butterworth Heinemann

Faure, G. O. (1999). The cultural dimension of negotiation: The Chinese case. Group decision and negotiation (8). Kluwer Academic Publishers. pp.187-215.

Fischer, R. (2004). Standardization to account for cross-cultural response bias: A classification of score adjustment procedures and review of the research in JCCP. Journal of Cross-Cultural Psychology, 35(3): 263-282.

Fisher, R., \& Ury, W. (1991). Getting to yes. New York: Penguin.

Foster, D. A. (1992). Bargaining across borders. New York: McGrawHill.

Ganesan, S. (1993). Negotiation strategies and the nature of channel relationships. Journal of Marketing Research, 30(May): 183203.

Gesteland, R. (1999). Cross-cultural business behavior. Hendon, VA: Copenhagen Business School Press.

Graham, J., Mintu, A., \& Rodgers, W. (1994). Explorations of negotiation behaviors in ten foreign cultures using a model developed in the United States. Management Science, 40(1): 72-95.

Hall, E. T., \& Hall, M. R. (1990). Understanding cultural differences: Germans, French, and Americans. Yarmouth, ME: Intercultural Press Inc.

Hampden-Turner, C., \& Trompenaars, F. (2000). Building crosscultural competence. New Haven: Yale University Press.

Hofstede, G. (1981). Culture's consequences: Comparing values, behaviors, institutions, and organizations across nations. Thousand Oaks: Sage Publications.

Hofstede, G. (2001). Culture's consequences: Comparing values, behaviors, institutions, and organizations across nations (2nd ed.). Thousand Oaks: Sage Publications.

House, R. J., Hanges, P. J., Javidan, M., Dorfman, P. W., \& Gupta, V. (2004). Culture, leadership, and organizations: The GLOBE study of 62 societies. Thousand Oaks: Sage.

Inglehart, R., Basañez, M., Díez-Medrano, J., Halman, L., \& Luijkx, R. (Eds.). (2004). Human beliefs and values: A cross-cultural sourcebook based on the 1999-2002 values surveys. Mexico City: Siglo XXI Editores.

Investor's Business Daily. March 1, 2004. A4. 
Kras, E. S. (1989). Management in two cultures: Bridging the gap between U.S. and Mexican managers. Yarmouth, ME: Intercultural Press.

Kurz, W. C. F. (2000). International business negotiations in the United States. In James R. Silkenat, \& The ABA guide to international business negotiations: A comparison of cross-cultural issues and successful approaches. Chicago: ABA Publishing.

Lewin, A. Y., Sakano, T., Stephens, C. U., \& Victor, B. (1995). Corporate citizenship in Japan: Survey results from Japanese firms. Journal of Business Ethics, 14(2): 83-101.

Lewis, R. D. (2004). Finland: Cultural lone wolf. Yarmouth, ME: Intercultural Press.

Lincoln, J. R., \& Kalleberg, A. L. (1985). Work organization and workforce commitment: A study of plants and employees in the US and Japan. American Sociological Review, 50(December): 738 760 .

Metcalf, L., \& Bird, A. (2004). Integrating the Hofstede dimensions and twelve aspects of negotiating behavior: A six-country comparison. In H. Vinken, J. Soeters, \& P. Ester (Eds.), Comparing cultures: Dimensions of culture in a comparative perspective. Amsterdam: Brill.

Moran, R., \& Stripp, W. (1991). Successful international business negotiations. Houston: Gulf Publishing.

Morrison, T., Conway, W. A., \& Borden, G. A. (1994). Kiss, bow, or shake hands: How to do business in sixty countries. Holbrook, MA: Bob Adams Inc.

Osland, J. S., \& Bird, A. (2000). Beyond sophisticated stereotyping: Cross-cultural sensemaking in context. Academy of Management Executive, 14: 1-12.

Perdue, B. C., \& Summers, J. O. (1991). Purchasing agents' use of negotiation strategies. Journal of Marketing Research, 28(May): 175-189.

Ronen, S., \& Shenkar, O. (1985). Clustering countries on attitudinal dimensions: A review and synthesis. Academy of Management Review, 10(3): 435-454.
Salacuse, J. (1991). Making global deals: Negotiating in the international marketplace. Boston: Houghton Mifflin.

Salacuse, J. (1998). Ten ways that culture affects negotiating style: Some survey results. Negotiation Journal, 14(3): 221-235.

Salacuse, J. W. (2003). The global negotiator: Making, managing, and mending deals around the world in the twenty-first century. New York: Palgrave Macmillan.

Shroff, C. (2000). International business negotiations in India. In James R. Silkenat, \& The ABA guide to international business negotiations: A comparison of cross-cultural issues and successful approaches. Chicago: ABA Publishing.

Smith, P. (2004). Acquiescent response bias as an aspect of cultural communication. Journal of Cross-Cultural Psychology, 35: 5061.

Van de Vijver, F., \& Leung, K. (1997). Methods and data analysis of comparative research. Thousand Oaks, CA: Sage.

Victor, D. (1992). International business communication. New York: Harper Collins Publishers.

Weiss, S. E. (2004). International business negotiation research: Revisiting the "bricks, mortar and prospects". In O. Shenkar, \& B. J. Punnett (Eds.), The handbook of international management research. Ann Arbor, MI: University of Michigan Press.

Weiss, S. E., \& Stripp, W. (1985). Negotiating with Foreign Business Persons: An Introduction for Americans with Propositions on Six Cultures. In Niemeier, S., Campbell, C. P., \& Dirven, R. Eds. The cultural context in business communication. Vol. 1998 (pp.51-118). Amsterdam: John Benjamins Publishing Company.

Winer, B. J., Brown, D. R., \& Michels, K. M. (1991). Statistical principles in experimental design. New York: McGraw-Hill.

Yang, K. S. (1988). Will societal modernization eventually eliminate cross-cultural psychological differences? In M. H. Bond (Ed.), The cross-cultural challenge to social psychology. London: Sage. 